This is the final peer-reviewed accepted manuscript of:

Burrascano, S.; de Andrade, R. B.; Paillet, Y.; Ódor, P.; Antonini, G.; Bouget, C.; Campagnaro, T.; Gosselin, F.; Janssen, P.; Persiani, A. M.; Nascimbene, J.; Sabatini, F. M.; Sitzia, T.; Blasi, C.: Congruence across taxa and spatial scales: Are we asking too much of species data? GLOBAL ECOLOGY AND BIOGEOGRAPHY 27. 1466$822 \mathrm{X}$

DOI: $10.1111 /$ geb.12766

The final published version is available online at:

http://dx.doi.org/10.1111/geb.12766

Rights / License:

The terms and conditions for the reuse of this version of the manuscript are specified in the publishing policy. For all terms of use and more information see the publisher's website.

This item was downloaded from IRIS Università di Bologna (https://cris.unibo.it/)

When citing, please refer to the published version. 


\title{
Congruence across taxa and spatial scales: Are we asking too much of species data?
}

\author{
S. Burrascano ${ }^{1 *}$ \\ R. B. de Andrade ${ }^{\text {* }}$ \\ Y. Paillet ${ }^{2}$ \\ P. Ódor ${ }^{3}$ Janssen $^{6}$ \\ G. Antonini ${ }^{4}$ A. \\ $\begin{array}{ll}\text { C. } \text { Bouget }^{2} & \text { T. Campagnaro } \\ & \end{array}$ \\ F. Gosselin ${ }^{2}$ \\ C. Blasi ${ }^{1}$ \\ M. Persiani ${ }^{1}$ \\ J. Nascimbene ${ }^{7}$ \\ F. M. Sabatini ${ }^{8}$ \\ T. Sitzia ${ }^{5}$
}

${ }^{1}$ Department of Environmental Biology, Sapienza University of Rome, Rome, Italy

${ }^{2}$ Irstea, UR EFNO, Nogent Sur Vernisson, France

${ }^{3}$ MTA Centre for Ecological Research, Institute of Ecology and Botany, Vácrátót, Hungary

${ }^{4}$ Department of Biology and Biotechnologies Charles Darwin, Sapienza University of

Rome, Rome, Italy

5Department of I.and, Environment, Agriculture and Forestry, Università degli

Studi di Padova, Padua, Italy

'Université Grenoble A pes, Irstea, UR LESSEM, Saint Martin d'Hères, France

'Department of Biological, Geological and Environmental Sciences (BiGeA), University of Bologna, Bologna, Italy

${ }^{8}$ Department of Geography, Humboldt Universität zu Berlin, Berlin, Germany

Correspondence

S. Burrascano, Department of

Environmental Biology, Sapien za University

of Rome, Rome, Italy.

Email: sabina.burrascano@uniroma1.it

Funding information

LIFE+ project FAGUS, Grant/Award number: 11/NAT/IT/00135; Hungarian Research Fund, Grant/Award number: OTKA K79158; IRSTEA: Conseil Général de I'l'sère; Bauges Natural Regional Park; French Ministry in charge of Ecology, Grant/Award number: GNB 10 MBGD BGF 1 CVS 092; Office National des For èts; Italian Ministry of Agricultural, Food and Forestry Policies, State Forestry Corps, Grant/Award number: 767/2008; Sapienza University of Rome, Grant/Award number: C26A15KE2T

\begin{abstract}
Aim: Biodiversity monitoring and conservation are extremely complex, and surrogate tav may represent proxies to test methods and solutions. However, cross-taxon correlations in species diversity (i.e., cross-taxon congruence) may vary widely with spatial scale. Our goal is to assess how cross-taxon congruence varies with spatial scale in European temperate forests. We expect that congruence in species diversity increases when shifting from fine to coarse spatial scales, with differences between species richness and composition, and across pairs of taxonomic groups.
\end{abstract}

Location: European temperate forests.

Time period: Present.

Major taxa studied: Vascular plants, bryophytes, birds, epiphytic lichens, saproxylic beetles and wood-inhabiting fungi.

Methods: We used field data (354 plots across 23 sites) encompassing Italy, France and Hungary, with species information for six taxonomic groups. We accounted separately for spatial grain (the size of elementary sampling unit) and extent (the geographical area included in the survey) and evaluated the relationships within all the possible pairs of taxa.

Results: Although no pair of taxa had its species richness consistently correlated across scales, we found no changes in the direction of correlations when analysing species composition. However, when increasing grain and extent, we did find a general increase in the magnitude of correlations in species composition and partial changes in significance, with plants having the highest number of significant correlations.

Main conclusions: Species richness congruence among taxa is strongly scale dependent owing to differences in the relative contribution of large- and small-scale processes across taxa. Cross-taxon congruence in species composition is scale dependent only for its magnitude, because life-history traits of individual species make responses to environmental factors similar across scales. Forest monitoring should consider multi-taxon sampling and limit the use of surrogates at specific spatial scales, especially for species richness. Sampling plant species composition in scattered plots across different sites may effectively summarize the whole community composition.

\section{KEYWORDS}

biodiversity, conservation, indicators, monitoring, multi-taxon, surrogates, temperate forests

•Authors contributed equally. 


\section{1 | INTRODUCTION}

The rapid decline of biodiversity throughout the world, with an estimated extinction rate $c .1,000$ times higher than the natural background rate (Pimm et al., 2014), configures as a worldwide 'biodiversity crisis' (Tittensor et al., 2014). The current expenditure for the protection of biodiversity in terrestrial sites amounts globally to $c$. US $\$ 10$ billion annually, but it should be increased by an order of magnitude to be efficient (McCarthy et al., 2012). The success of any conservation initiative, however, relies on the availability of objective and timely information on biodiversity (Tittensor et al., 2014), which is also extremely expensive. The four main global biodiversity databases costed c. US\$160 million from 1979 to 2013 , and an additional US\$114 million would be needed to reach the desirable data coverage (Juffe-Bignoli et al., 2016).

In this perspective, the use of a limited, yet ecologically relevant, number of indicators is commonly advocated to evaluate and monitor the impact and long-term effectiveness of conservation initiatives (Lindenmayer et al., 2014). Indicators can derive from habitat or environmental features (i.e., habitat based), or from the features of one or more species (i.e., taxa based). Even if habitat-based indicators are generally perceived as more cost-effective (Lindenmayer et al., 2014; Pearson, 1994), taxa-based indicators are more likely to account for a wide range of biological patterns and processes (Meier, Edwards, Kienast, Dobbertin, \& Zimmermann, 2011). Identifying taxa-based indicators of groups that are costly to sample and/or identify represents an effective shortcut in biodiversity surveys and monitoring (Gao, Nielsen, \& Hedblom, 2015). For instance, diversity patterns and taxonomy of relatively well-known taxa, such as birds and vascular plants, may be used effectively to draw information on several overlooked organisms, such as fungi or insects (Scheffers, Joppa, Pimm, \& Laurance, 2012). The potential for the use of taxa-based indicators relies on the strength of cross-taxon congruence (i.e., the correlation in patterns of species richness and/or composition of different taxonomic groups across sites). Assessing the general validity and robustness of cross-taxon congruence across biogeographical regions and scales is, however, still an open issue in conservation biology (Lewandowski, Noss, \& Parsons, 2010; Westgate, Barton, Lane, \& Lindenmayer, 2014).

Congruence between taxa may be driven by mechanisms operating at very different spatial scales, such as biotic interactions and similar responses to the same or covarying environmental factors, making cross-taxon relationships scale dependent (Wolters, Bengtsson, \& Zaitsev, 2006). Recent research has found inconclusive results on the effects of spatial extent (the geographical area that is represented by the sample) and grain (the size of each sampling unit) on cross-taxon congruence. For taxa such as butterflies and birds, congruence increased with larger sampling grains, but no effect was found from increasing extent (Pearson \& Carroll, 1999). Meanwhile, multitaxonomic analyses found responses to an increase in grain to be idiosyncratic to each taxon (Hess et al., 2006). Additionally, different diversity metrics have unique responses to changes in scale. The review by Westgate, Tulloch, Barton, Pierson, and Lindenmayer (2017) found extent to affect congruence in both species richness and composition, whereas grain exerted no significant effect on species composition.
These results, however, do not represent a definitive framework to understand the variation in cross-taxon congruence across spatial scales, as they derive either from local studies or from meta-analyses comparing the results of different studies, rather than on a consistent exploration of the same data across a broad range of spatial scales.

Here, we assess how cross-taxon congruence varies across different spatial scales in European temperate forests by using a comprehensive set of field data that encompasses a wide geographical range. Our dataset includes information on species diversity for six taxonomic groups, including both well-known groups (vascular plants, birds and saproxylic beetles) and groups for which knowledge is relatively limited (wood-inhabiting fungi, bryophytes and epiphytic lichens). We account separately for differences in spatial grain and extent and we evaluate the cross-taxon relationships in species richness and composition within all the possible pairs of taxonomic groups. Our general hypothesis is that cross-taxon congruence in European temperate forests increases when shifting from fine to coarse spatial grains and extents. We expect this general trend to have different effects on correlations of species richness and species composition between taxonomic groups. We also expect the magnitude of the effect of scale to vary widely across different pairs of taxonomic groups.

\section{METHODS}

\section{1 | Study sites}

The study area spans across France, Italy and Hungary (Figure 1) and includes 354 plots clustered in 23 forest areas (hereafter, 'sites') of c. $200-400 \mathrm{~km}^{2}$ (Table 1), with altitudes ranging from 150 to $1700 \mathrm{~m}$ a.s.l.. Substrates include sedimentary rocks (limestones, dolomites, marls and flysch) in the French and Italian sites, and are formed by alluvial gravel mixed with sand and loess in the Hungarian site. All sites belong to the temperate region, with bioclimates varying from hyperoceanic to continental (Rivas-Martinez \& Rivas-Saenz, 2009). Annual mean temperature varies from 5 to $14{ }^{\circ} \mathrm{C}$, with minimum values in the French Alps and maximum values in the southernmost site of the Italian peninsula (i.e., Cilento). Annual precipitation varies from c. 600 to c. $1,900 \mathrm{~mm}$ in the French Alps.

The sites include several European deciduous forest types, most of which are of conservation concern according to the European Directive for the maintenance of biodiversity (i.e. Per conto di thomascampagnaro, Habitats Directive 92/43/EEC). Forest types range from mesophytic deciduous forests, beech and montane beech forests, to thermophilous deciduous forests. The great majority of data were collected in forests dominated or co-dominated by European beech (Fagus sylvatica L.) or by deciduous oaks (Quercus cerris L., Quercus pubescens L., Quercus frainetto L., Quercus petraea Matt. (Liebl.) and Quercus robur L.). Several sites are co-dominated by conifer species, namely silver fir (Abies alba L.), Norway spruce (Picea abies L.) and Scots pine (Pinus sylvestris L.). These forests have diverse structural characteristics and include one-, two- and multi-layered stands. Their history and recent management also vary greatly, from coppice to shelterwood and selection forestry systems. Part of the studied forests were withdrawn from 


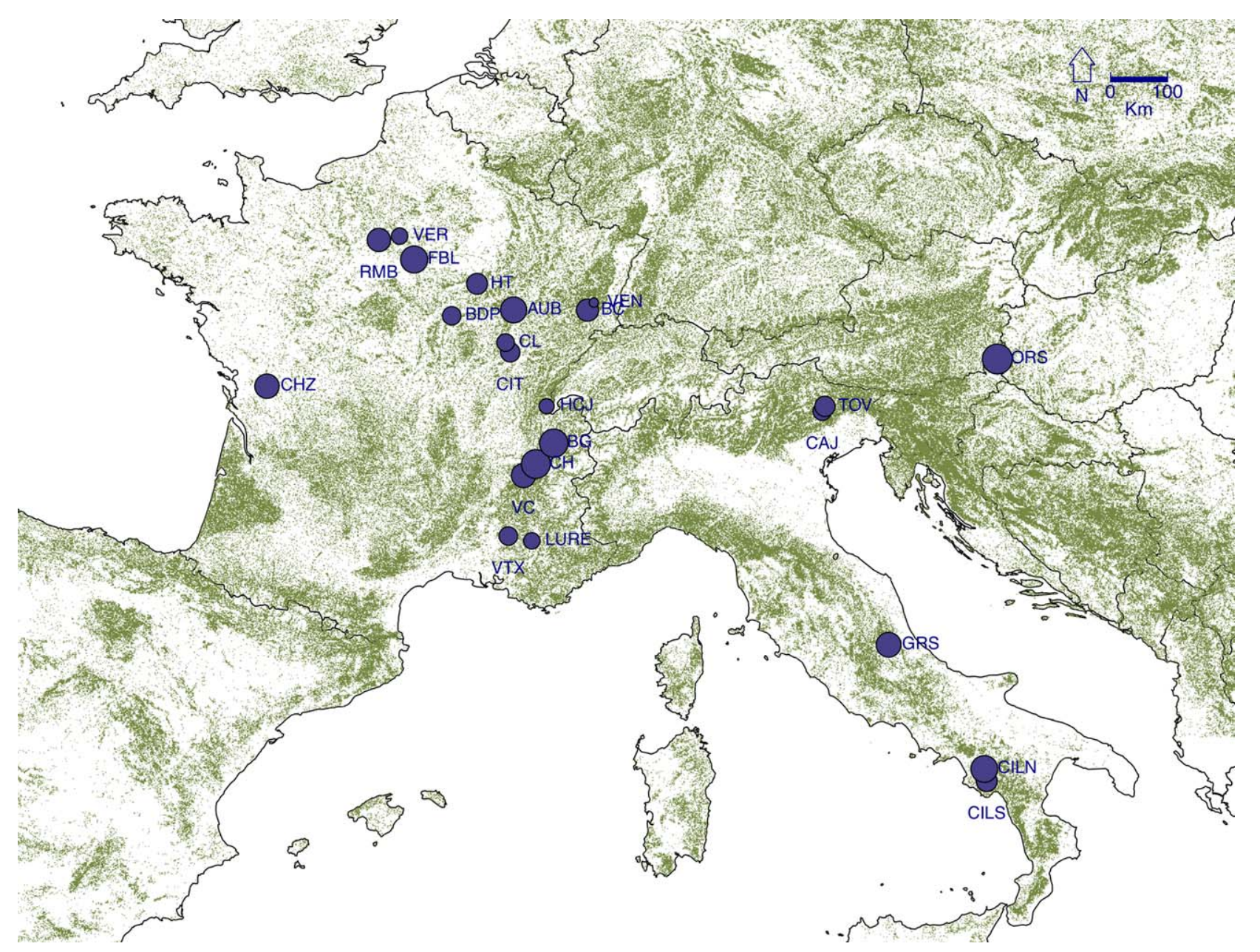

FIGURE 1 Distribution of study sites in Europe. Forest cover is indicated by green colour (from the Joint Research Centre, http://forest. jrc.ec.europa.eu; Kempeneers, Sedano, Seebach, Strobl, \& San-Miguel-Ayanz, 2011). The size of the dots is $\log _{10}$-proportional to the number of plots at each site. For complete site names and number of plots, refer to Table 1. [Color figure can be viewed at wileyonlinelibrary.com]

management either recently (20 years) or for a relatively long time (60150 years).

\section{2 | Sampling of species diversity}

This study is based on multi-taxonomic species data that were collected for different research projects and standardized for the present study. Sampling was performed through similar protocols across sites (see Supporting Information Appendix S1 for details). Complete lists of vascular plant species occurring in plots ranging from 314 to $1256 \mathrm{~m}^{2}$ were compiled. Data for lichens include only epiphytic species; likewise, only wood-inhabiting fungi were considered. Bryophytes were sampled on different substrates (standing trees, deadwood, rocks and ground). Birds were sampled by point counts (see Bouvet et al., 2016). Finally, saproxylic beetles were sampled by window-flight interception traps, emerging traps and Winkler extractors (see Janssen et al., 2016). We checked and homogenized species lists for plants by using The Plant List (http://www.theplantlist.org); we used ITALIC for lichens (Nimis \& Martellos, 2008), Index Fungorum for fungi (http://www. indexfungorum.org/names/names.asp), Hodgetts (2015) for bryophytes, and several online resources for animals (http://www.fauna-eu. org/; http://www.gbif.org/; http://www.organismnames.com/; https:// inpn.mnhn.fr/accueil/index).

\section{3 | Statistical analyses}

\subsection{1 | Data preparation}

To analyse congruence patterns, we used pairwise raw correlation coefficients within 15 possible pairs of taxonomic groups. For species richness, we used pairwise Pearson's correlation and for community composition, correlations derived from Mantel tests based on Sørensen dissimilarity matrices (Peres-Neto \& Jackson, 2001) in the package 'vegan' (Oksanen et al., 2016) in R environment version 3.3.3.

To test the effects of scale on congruence between taxa, correlation indices were calculated at different combinations of sampling grains (the size of elementary sampling unit) and extents (the geographical area comprised by the survey): plot grain and site extent (PG-SE) replicated in the 23 sites across the continent; plot grain and continental extent (PG$\mathrm{CE}$ ) across the whole set of possible plots; and site grain and continental extent (SG-CE) with plot species data pooled together at the site scale. At the plot grain, we used observed species richness, except for saproxylic beetles (the only taxa with abundance data), for which we estimated 
TABLE 1 Site description

\begin{tabular}{|c|c|c|c|c|c|c|c|c|c|c|c|}
\hline $\begin{array}{l}\text { Source } \\
\text { dataset }\end{array}$ & $\begin{array}{l}\text { Site } \\
\text { code }\end{array}$ & Full name & $\begin{array}{l}\text { Number } \\
\text { of plots }\end{array}$ & Substrate & $\begin{array}{l}\text { Mean annual } \\
\text { temperature }\left({ }^{\circ} \mathrm{C}\right)\end{array}$ & $\begin{array}{l}\text { Mean annual } \\
\text { rainfall }(\mathrm{mm})\end{array}$ & $\begin{array}{l}\text { Mean } \\
\text { elevation }\end{array}$ & $\begin{array}{l}\text { Mean } \\
\text { aspect }\end{array}$ & $\begin{array}{l}\text { Mean } \\
\text { slope }\end{array}$ & Longitude & Latitude \\
\hline FR All & AUB & Auberive & 22 & Limestone & 9 & 800900 & 239 & 453 & 6 & 3952322 & 2749460 \\
\hline FR All & BDP & Bois du Parc & 9 & Limestone & 10.9 & 650750 & 227 & 184 & 7 & 3843663 & 2739193 \\
\hline IT NE & CAI & Cajada forest & 9 & $\begin{array}{l}\text { Dolomite/ } \\
\text { limestone }\end{array}$ & 7.2 & $1,3001,500$ & 1,209 & 70 & 25 & 4493953 & 2571625 \\
\hline FR All & $\mathrm{CHZ}$ & Chizé & 18 & Limestone & 12 & 800900 & 230 & 83 & 3 & 3519394 & 2615560 \\
\hline FR All & CIT & Citeaux & 10 & Alluvial deposits & 10.9 & 700800 & 166 & 234 & 2 & 3946333 & 2675023 \\
\hline FR All & $\mathrm{CL}$ & Combe Lavaux & 8 & Limestone & 9.1 & 800900 & 162 & 567 & 9 & 3938205 & 2692135 \\
\hline FR All & FBL & Fontainebleau & 25 & Acidic sands & 10.5 & 600700 & 201 & 133 & 4 & 3777782 & 2838013 \\
\hline FR All & $\mathrm{HCJ}$ & $\begin{array}{l}\text { Haute-Chaine } \\
\text { du Jura }\end{array}$ & 6 & Limestone & 7.5 & $1,3001,400$ & 100 & 1,097 & 32 & 4010075 & 2580481 \\
\hline FR All & HT & Haut Tuileau & 12 & Alluvial deposits & 10 & 650750 & 210 & 163 & 4 & 3888153 & 2795234 \\
\hline HU & ORS & Orseg & 35 & Gravel/loess & 9.2 & 700800 & 297 & 134 & 10 & 4801240 & 2663285 \\
\hline $\begin{array}{l}\text { п CIL/ } \\
\text { ா FAGUS }\end{array}$ & CILN & Cilento $\mathrm{N}$ & 24 & Limestone & 10.1 & $718 \quad 1,250$ & 1,176 & 122 & 22 & 4778341 & 1944509 \\
\hline IT CIL & CILS & Cilento S & 12 & Limestone/flysch & 11.2 & 700 & 1,157 & 158 & 43 & 4782680 & 1923206 \\
\hline IT FAGUS & GRS & Gran Sasso & 19 & Limestone & 9.1 & $1,0621,097$ & 1,351 & 251 & 41 & 4610475 & 2162527 \\
\hline FR All & VER & Verrières & 7 & $\begin{array}{l}\text { Acidic sands } \\
\text { marls }\end{array}$ & 9.6 & 600700 & 211 & 173 & 2 & 3752114 & 2879081 \\
\hline FR All & VTX & Ventoux & 9 & Limestone & 7.9 & $1,0001,100$ & 147 & 1,335 & 27 & 3943032 & 2353297 \\
\hline
\end{tabular}

Note. Site code as reported in Figure 1, number of plots, lithological, climatic and topographic parameters and coordinates (in Universal Transverse Mercator) for each site.

richness by extrapolating or interpolating observed richness to the average number of individuals per plot ( $n 196$ individuals; see Supporting Information Appendix S2 for differences in sampling efforts). At the site grain, we used estimated species richness for all taxa based on extrapolation and interpolation of accumulation curves. The estimated richness was extrapolated or interpolated based on presence/ absence data to the average number of plots per site (14), except for saproxylic beetles, for which we used the average number of individuals per site ( $n$ 2,753). Extrapolation and interpolation of accumulation curves were calculated using the 'iNEXT' package (Hsieh, Ma, \& Chao, 2016). Analyses of species composition were based on species lists aggregated at the different scales of interest. The number of sampling units (plots or sites, depending on the scale) for each pair of taxa can be found in Supporting Information Appendix S3.

\subsection{2 | Effect size analyses}

Compared with classical linear modelling using a diversity index (i.e., species richness) of a given taxon as a response variable against its counterpart for another taxon as an explanatory variable, correlation coefficients benefit from a symmetrical role between taxa (i.e., they do not depend on which taxon is used as an explanatory or response variable). The correlation coefficients were used as response variables at the different scales for both species richness and composition. We derived overall correlations for each pair of taxonomic groups from a random effect model (function 'rma', 'metafor' package; Viechtbauer, 2010) and represented effect sizes for each pair and their corresponding $95 \%$ confidence intervals (Cls). The use of effect size (i.e., a relevant interpretation of an estimated magnitude of an effect or the biological importance of the effect; Nakagawa \& Cuthill, 2007) is assumed to 

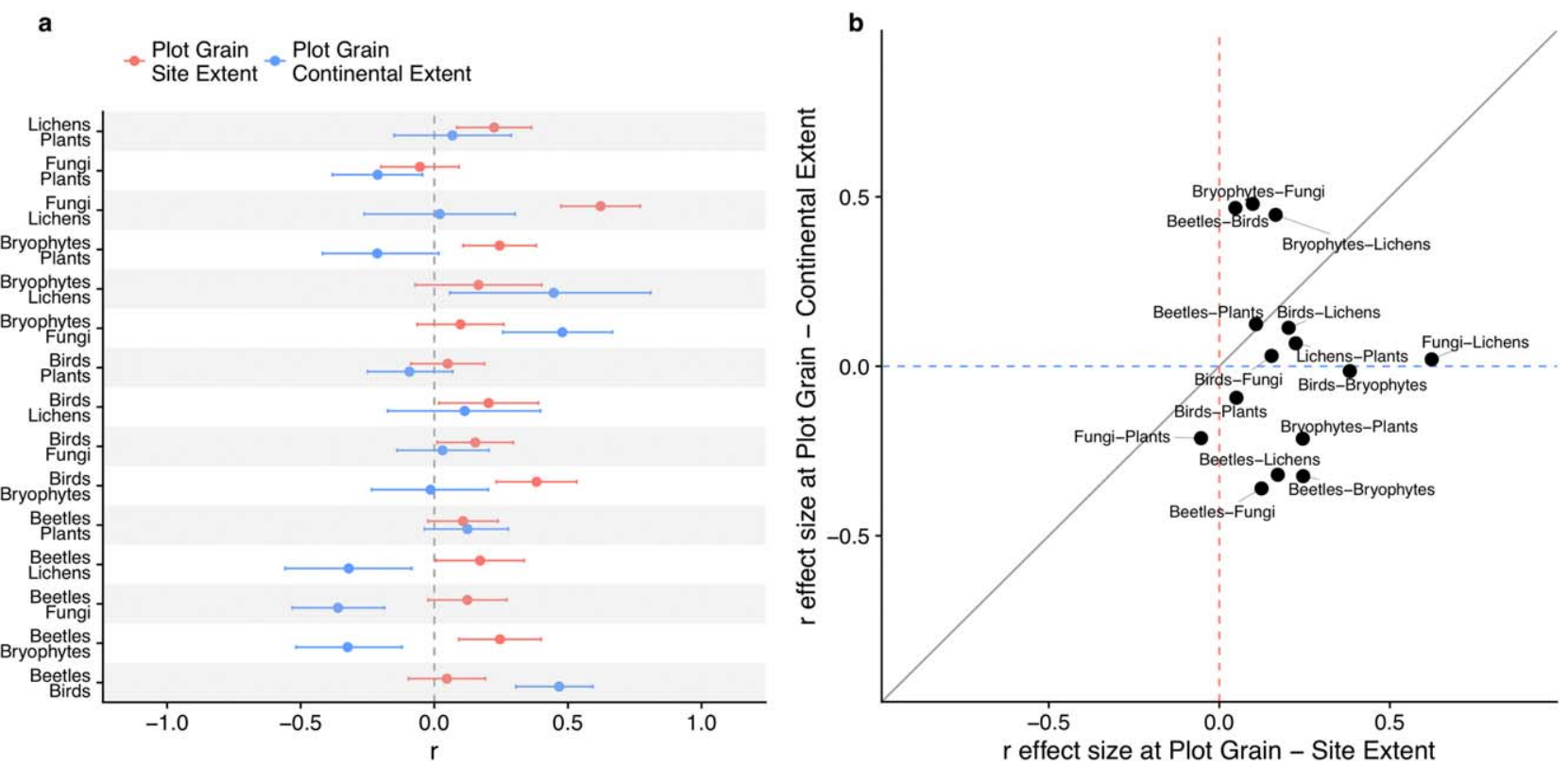

FIGURE 2 Effect size estimations for Pearson's correlation coefficients among species richness of different taxa at plot grain and continental (PG-CE) and site (PG-SE) extents in temperate European forests. (a) Effect sizes and 95\% confidence intervals. At the PG-CE scale, we estimated confidence intervals by resampling a corresponding number of plots for each site of the PG-SE scale and averaged the results for 999 repetitions. (b) Effect size change in a coordinate system. Plots close to the grey line indicate pairs for which the congruence relationship does not change with extent. Blue and red dotted lines indicate no correlation between scales. Note that, owing to resampling estimations of confidence intervals, they may vary when compared with Figure 4 for the PG-CE scale. [Color figure can be viewed at wileyonlinelibrary.com]

provide more informative results, enables comparisons with previous quantitative results (e.g., Westgate et al., 2014) and accounts for the differences in sampling effort (Nakagawa \& Cuthill, 2007). This process was repeated for each extent-grain combination. Correlation at the SG-CE scale was not calculated for bryophytes-lichens, because only three sites had data for both taxa.

Given that the sample size varies widely across scales (e.g., a maximum of 310 samples at plot grain versus 22 samples at site grain for plants-beetles correlations; Supporting Information Appendix S3), we resampled the dataset at plot grain-continental extent to have comparable sample sizes and variances for each analysis. For extent comparison, PG-CE was resampled to reflect the plot grain-site extent data structure (i.e., random subsamples in number corresponding to the number of sites, and sizes corresponding to the number of plots across sites; e.g., concomitant data for birds and lichens at PG-SE scale were available in six sites of nine, 35, 24, 12, 19 and 11 plots, respectively; PG-CE was resampled as six subsamples of nine, 35, 24, 12, 19 and 11 random plots, regardless of site). For grain comparison, PG-CE was resampled to reflect the site grain-continental extent data structure (i.e., one subsample of one random plot from each site; e.g., beetles and birds had data in 19 sites at SG-CE; PG-CE was resampled as one subsample of 19 plots, one from each site). All resampling procedures were repeated 999 times. We averaged correlation effect sizes and calculated the corresponding $95 \% \mathrm{Cls}$. Owing to the different resampling procedures, the PG-CE results display equal correlation values, but different $\mathrm{Cls}$ when contrasting extent and grain. We considered a correlation to be significant when zero was not included in the $\mathrm{Cl}$.

\section{3 | RESULTS}

\section{$3.1 \mid$ Changing the extent}

When analysing species richness at the PG-SE, we found congruence for eight out of 15 pairs of taxa (Figure 2a; i.e., beetles-bryophytes, beetles-lichens, birds-bryophytes, birds-fungi, birds-lichens, bryophytes-plants, fungi-lichens and lichens-plants, all of which resulted in positive correlations). Fungi-lichens had the greatest correlation effect

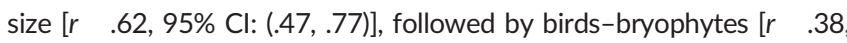
95\% Cl: $(.23, .53)]$ and beetles-bryophytes $[r \quad .25,95 \%$ Cl: $(.09, .40)]$. By increasing the extent from site (PG-SE) to continental scale (PG-CE),

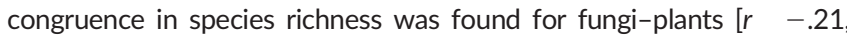

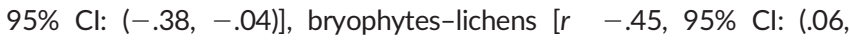
$.81)]$, bryophytes-fungi $[r \quad .48,95 \% \mathrm{Cl}:(.26, .67)]$, beetles-lichens

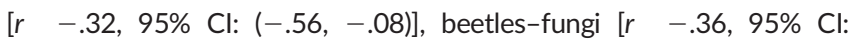
$(-.55,-.08)]$, beetles-bryophytes $[r \quad-.32,95 \% \mathrm{Cl}:(-.52,-.12)]$ and beetles-birds [ $r \quad .47,95 \% \mathrm{Cl}:(.30, .59)]$. Only beetles-lichens and beetles-bryophytes were congruent at both extents (PG-SE and PG-CE), although not consistently, as both changed their correlation effect size from positive to negative. No discernible overall response to changing the extent was found for species richness congruence (Figure 2b).

For community composition at PG-SE, we found low but significant congruence between vascular plants and all other taxa except birds (Figure 3a). The highest congruence was between plants and lichens $\left[\begin{array}{ll}r & .37\end{array}\right.$ $95 \% \mathrm{Cl}$ : $(.17, .57)]$. Additionally, the species composition of lichens was

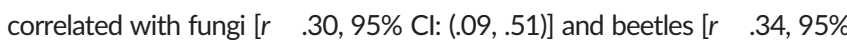
$\mathrm{Cl}:(.15, .52)]$. By increasing the scale of the extent from site to 
a

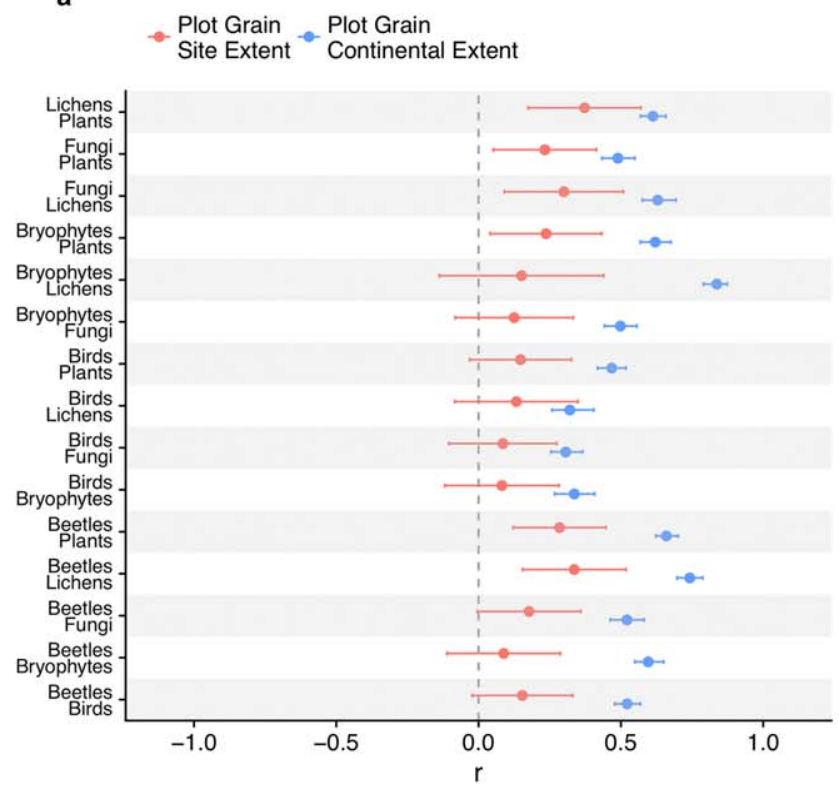

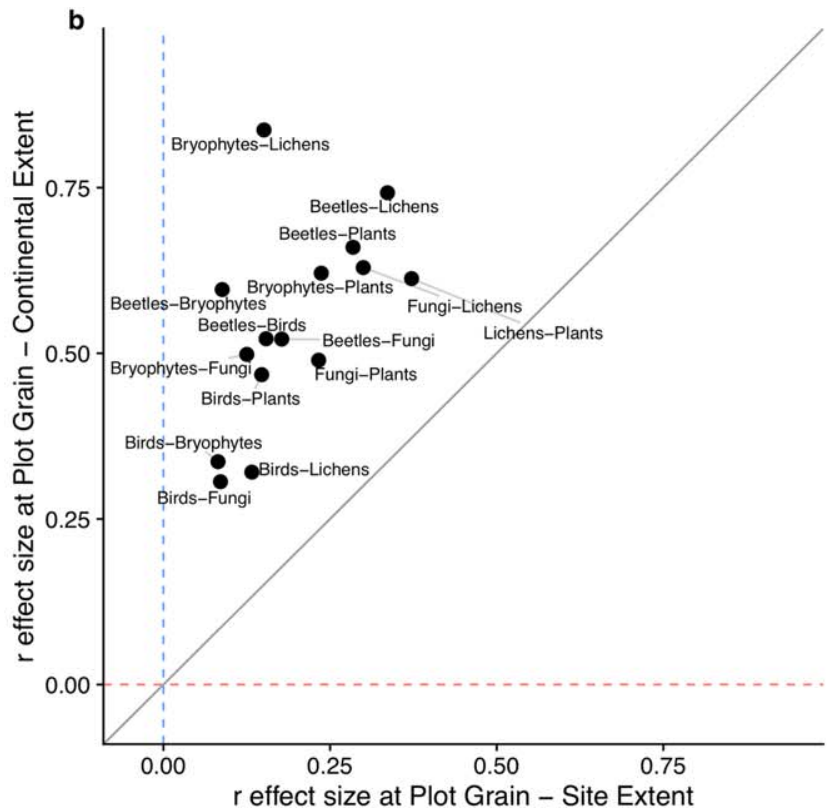

FIGURE 3 Effect size estimations for Mantel correlation coefficients among spatial patterns of community composition of different taxa at plot grain and continental (PG-CE) and site (PG-SE) extents in temperate European forests. (a) Effect sizes and 95\% confidence intervals. At the PG-CE scale, we estimated confidence intervals by resampling a corresponding number of plots for each site of the PG-SE scale and averaged the results for 999 repetitions. (b) Effect size change in a coordinate system. Plots close to the grey line indicate pairs for which the congruence relationship does not change with extent. Blue and red dotted lines indicate no correlation between scales. Note that, owing to resampling estimations of confidence intervals, they may vary when compared with Figure 5 for the PG-CE scale. [Color figure can be viewed at wileyonlinelibrary.com]

continental, the patterns of species composition of all pairs were highly congruent, with the strongest correlation between bryophytes and lichens $[r \quad .84,95 \% \mathrm{Cl}:(.79, .87)]$. Increasing the extent caused no changes in the direction of correlations but had the overall effect of increasing the magnitude of community composition congruence (Figure 3 b), along with partial changes in significance (nine out of 15 pairs shifted from non-significant to significant when increasing the extent).

\section{2 | Changing the grain}

At the PG-CE, no pair of taxa resulted in significant congruence in species richness (Figure 4a). By increasing from the plot to the site grain (SG-CE), we found four significantly congruent pairs of taxa, namely

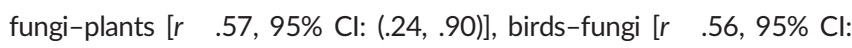
$(.22, .90)]$, beetles-plants $[r \quad .49,95 \% \mathrm{Cl}:(.17, .82)]$ and, more marginally, beetles-birds [r $\quad .39,95 \% \mathrm{Cl}:(.00, .78)]$.

Increasing the grain from plot to site had little effect on congruence patterns in species composition (Figure 5), causing no changes in direction and slight changes in magnitude. Plants had the highest number of significant positive correlations (with five other taxa) at both grains, but with low coefficients (ranging from .23 to .37). Beetlesbryophytes was the only pair for which species composition showed no congruence at the plot grain but positive congruence at the site grain $[r \quad .74,95 \% \mathrm{Cl}(.47,1.00)]$. At both plot and site grains, no congruence was found only for fungi-lichens, bryophytes-fungi, birdslichens and birds-bryophytes, which were generally pairs with a small number of sampled sites.

\section{DISCUSSION}

Our results support, in part, the hypothesis that cross-taxon congruence in species diversity generally increases with extent and grain. Increasing the extent resulted in a similar number of significant congruences in species richness, but between completely different taxa, also with several changes in the direction of the correlations. For species composition, the number of significant congruences increased with extent, and the direction of the correlation did not change. Increasing the grain had a small positive effect on both richness and composition and did not change the general correlation pattern.

The strong effect of spatial scale on species richness is probably attributable to the different contribution of processes operating in forest ecosystems at the plot, site and continental scales from those related to the fine-scale pattern of forest structural components to those depending on site characteristics such as biomass accumulation and broad biogeographical factors. Large-scale processes, such as speciation, migration and dispersal, determine regional species pools, whereas local diversity is governed by filtering of abiotic and biotic factors (Zobel, Szava-Kovats, \& Pärtel, 2011). Hence, when comparing different extents, the emerging patterns would be strongly dependent on the characteristics of this filtering within and among sites. Based on our results, these processes change across taxa, resulting in a high degree of scale dependency for cross-taxon congruence in species richness. Groups including species with wide home ranges, such as birds, are likely to respond greatly to landscape-level patterns, such as land use and matrix composition (Bouvet et al., 2016; Campagnaro, Frate, 
a

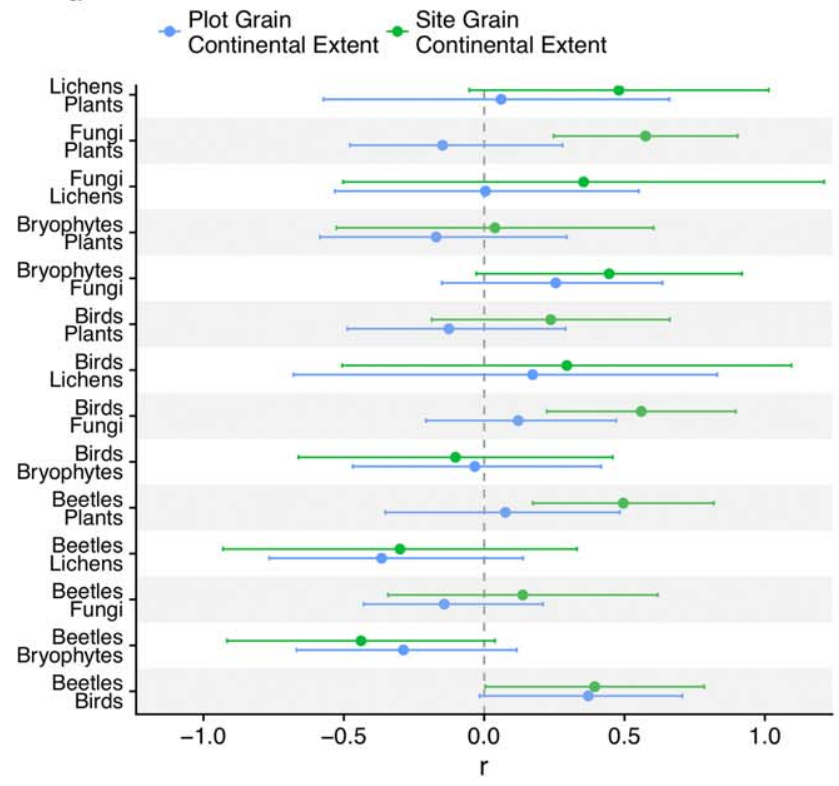

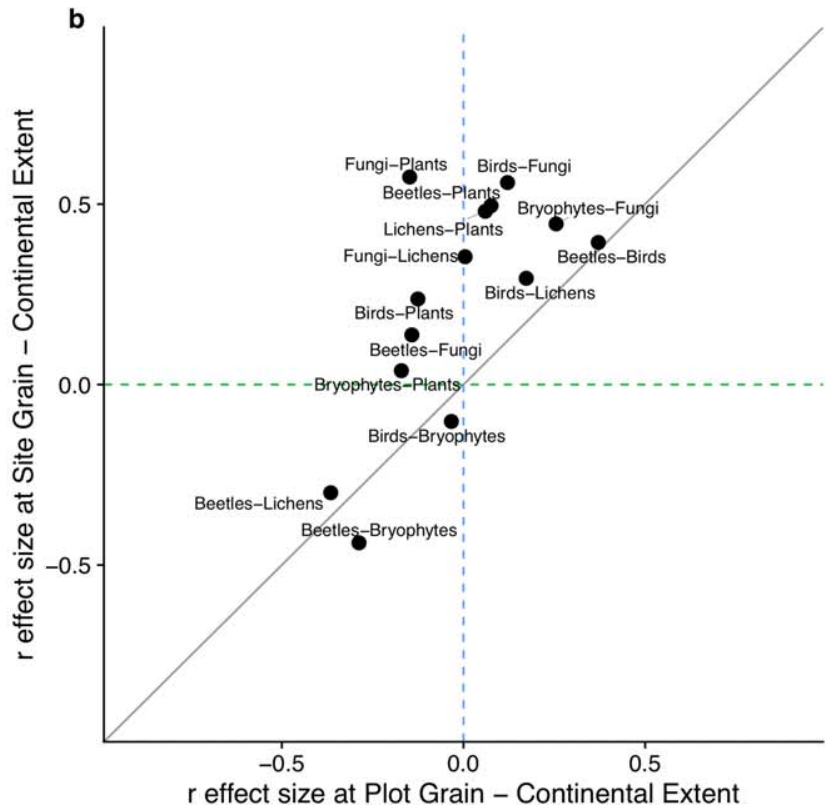

FIGURE 4 Effect size estimations for Pearson's correlation coefficients among species richness of different taxa at plot (PG-CE) and site (SG-CE) grains and continental extent in temperate European forests. (a) Effect sizes and 95\% confidence intervals. At the PG-CE scale, we estimated confidence intervals by resampling a number of plots corresponding to the number of sites at the SG-CE scale and averaged the results for 999 repetitions. (b) Effect size change in a coordinate system. Plots close to the grey line indicate pairs for which the congruence relationship does not change with extent. Blue and green dotted lines indicate no correlation between scales. Note that, owing to resampling estimations of confidence intervals, they may vary when compared with Figure 2 for the PG-CE scale. [Color figure can be viewed at wileyonlinelibrary.com]

Carranza, \& Sitzia, 2017). In contrast, other taxa, whose activity is mostly limited to a small extent (i.e. plants or beetles), are likely to be more susceptible to local heterogeneity patterns. The richness of saproxylic organisms, for instance, is likely to be influenced greatly by deadwood diversity and stand openness (e.g., Bouget, Larrieu, Nusillard, \& Parmain, 2013).
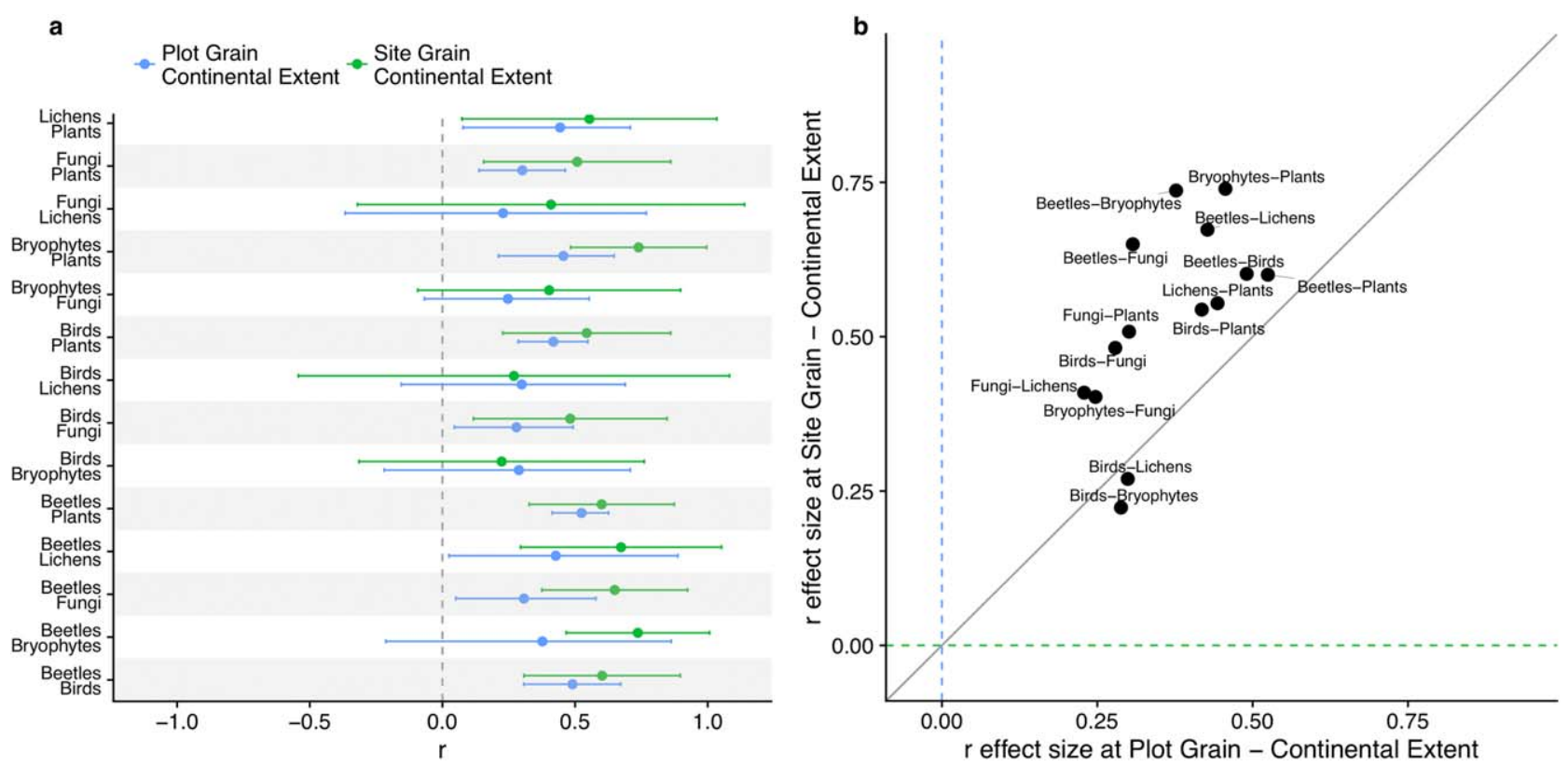

FIGURE 5 Effect size estimations for Mantel correlation coefficients among spatial patterns of community composition of different taxa at plot (PG-CE) and site (SG-CE) grains and continental extent in temperate European forests. (a) Effect sizes and 95\% confidence intervals. At the PG-CE scale, we estimated confidence intervals by resampling a number of plots corresponding to the number of sites at the SG-CE scale and averaged the results for 999 repetitions. (b) Effect size change in a coordinate system. Plots close to the grey line indicate pairs for which the congruence relationship does not change with extent. Blue and green dotted lines indicate no correlation between scales. Note that, owing to resampling estimations of confidence intervals, they may vary when compared with Figure 3 for the PG-CE scale. [Color figure can be viewed at wileyonlinelibrary.com] 
Patterns of species composition, however, do not necessarily overlap with variations in species richness (Supp \& Ernest, 2014). To explain our results, we rely on the general hypothesis that when species identity is factored in, local and regional scales are more interdependent, because the responses of individual species to biotic and abiotic factors are linked to species traits (e.g., traits that determine species' adaptations to climate influence their response to this factor at different scales; Cornell \& Harrison, 2014). Therefore, the direction and relevance of this response is likely to hold true across scales. Accordingly, we found that patterns of cross-taxon congruence for species composition are only partly scale dependent, as the increase in scale increases the magnitude but does not change the direction of the correlations.

\section{1 | Cross-taxon congruence across spatial scales}

By moving from the finest scale (PG-SE) to the coarser grain (SG-CE) and wider extent (PG-CE), cross-taxon congruence in species richness is highly variable. At the site extent (PG-SE), the correlations in patterns of species diversity probably derive from the fact that pairs of taxa share a similar or opposite (in case of a negative correlation) response to fine-scale environmental variables. In forests, fine-scale patterns of species diversity are strongly driven by forest structure parameters, such as tree cover, amount of deadwood, tree size distribution and the occurrence of habitat trees (Janssen, Fortin, \& Hébert, 2009; Sabatini, Burrascano, Tuomisto, \& Blasi, 2014). For instance, at the site extent (PG-SE), species richness is congruent between beetles and lichens, and between beetles and bryophytes probably because these groups take advantage of the availability of rare and scattered stand structural attributes, such as large living, senescent or dead trees, relatively rare tree species, and tree-related microhabitats (Kiraly, Nascimbene, Tinya, \& Odor, 2013).

By increasing the grain from plot to site, the fine-scale drivers (e.g., stand structure) that operate at the plot grain are likely to be overridden by factors related to site characteristics and demographic processes. Both environmental features, such as soil type and local climate, and biotic factors, such as dispersal patterns, seed bank and competition, are recognized as important in the distribution of forest species at this scale (Miller, Mladenoff, \& Clayton, 2002; Svenning \& Skov, 2002). As the correlations found in both species richness and composition at the site grain scale (SG-CE) are all positive, they could derive from the fact that some forest types or specific sites host higher species richness for several taxonomic groups. For instance, forests dominated by conifer species and, to a certain extent, European beech, produce a litter whose characteristics determine a low suitability for understorey vascular plant species (Barbier, Gosselin, \& Balandier, 2008), with a potential detrimental effect on the species richness of interacting taxonomic groups (e.g., saproxylic beetles and bryophytes; Márialigeti, Németh, Tinya, \& Ódor, 2009). Independently of specific forest types, species richness of certain taxa can increase in those sites where the overstorey is especially diverse, as demonstrated for understorey vascular plants (Barbier, Chevalier, Loussot, Bergès, \& Gosselin, 2009; Burrascano et al., 2018), birds (James \& Wamer, 1982) and wood-inhabiting fungi (Heilmann-Clausen, Aude, \& Christensen, 2005). For saproxylic organisms specifically, higher tree species richness means a greater diversification of resources (Bouget et al., 2013). However, to be suitable for a high number of both wood-inhabiting fungi and saproxylic beetle species, a forest should not only be rich in tree species, but also provide different wood substrates in terms of age, senescence and decay stage (Bouget et al., 2013). Hence, sites including late-successional and old-growth stands (i.e., stands that have accumulated a high structural complexity and deadwood in different decay stages) are expected to host a higher species richness of these taxonomical groups (Burrascano, Sabatini, \& Blasi, 2011).

The patterns observed when shifting from the local to the regional scale are marked by local ecological processes being replaced by biogeographical ones (Zobel et al., 2011). Therefore, by increasing the extent from site to continental, it is likely that broad-scale factors (e.g., climatic and biogeographical patterns) are more decisive in determining congruence patterns in species richness and composition when compared with the effect of those fine-scale determinants directly or indirectly related to forest structure (e.g., microclimatic conditions, occurrence of specific elements). The inclusion of a wider extent and, consequentially, broader ecological gradients, increases congruence for all pairs of taxa, as expected. However, we found opposite patterns for some pairs. The positive species richness correlations between beetles and bryophytes and between beetles and lichens at the site extent might depend on light availability and microclimatic conditions. These relationships, however, become negative at the continental extent, probably in response to large-scale climatic differences (Figure 2). Species composition, instead, showed a general increase in congruence when moving towards broad scales, probably as a result of the increasing influence of differences among broad forest types on the composition of biological communities (Soininen, McDonald, \& Hillebrand, 2007; Willis \& Whittaker, 2002).

\section{2 | Implications for monitoring and conservation}

Our results indicate that evaluating an array of spatial scales and biodiversity metrics can bring complementary, and sometimes contrasting, information on multi-taxon congruence in European temperate forests. Our findings support the need to adopt multi-taxon approaches that can provide information on different taxonomic groups, whose interactions do not result in a congruent diversity pattern. However, habitatbased indicators should be investigated further, because at smaller grain scales the diversity of fungi, lichens, birds and saproxylic beetles could be linked to the availability of specific structural attributes.

At broader spatial scales, congruence in patterns of species richness and composition might reflect biogeographical factors that do not have a key role in the evaluation of biodiversity-friendly practices and management. The range of spatial extents considered in our analysis (from c. 200-400 km² sites in PG-SE to one large combined sampling comprising Italy, France and Hungary in PG-CE and SG-CE), although extreme, is likely to occur when plot-grain data are aggregated for continental conservation initiatives and decisions (e.g., ForestBIOTA in Europe; http://www.forestbiota.org/). Based on our results concerning species richness congruence of forest organisms, these data could not 
be used at the continental scale to investigate cross-taxon congruence patterns or to develop biological indicators based on these pattems.

Although previous studies have shown that local pattems of congnuence can rarely be extrapolated to other regions (Westgate et al., 2014), when examining species composition at the PG-SE scale our results indicate consistent cross-taxon associations in many sites, especially between plants and other taxa. This is not surprising, because plants are the major structural and functional component of forest ecosystems and therefore influence forest structure and nutrient cycling (e.g., vertical stratification; Tews et al., 2004). Previous studies also support vascular plants as good surrogates of spatial composition patterns in temperate forests (Blasi et al., 2010; Sætersdal et al., 2004) and in other biomes (Andrade et al., 2014), although contradictory results have also been pointed out (e.g., Santi et al., 2010). Even if with low correlation coefficients, the value of vascular plant species composition as a surrogate for the composition of several other taxa across different spatial scales is good news for those conservation initiatives that base habitat interpretation and monitoring on plant diagnostic species (e.g., Habitats Directive within the European Union and Natura 2000 implementation).

Compared with plot level, samples at the site grain are much more representative of the local species pool of each taxon, but still subject to high species tumover owing to the geographical extent of the analysis. However, we found cross-taxon congruence in species composition to hold across different grains for many pairs of taxonomic groups, apart from some pairs with a low number of sites with co-occurring samples. This is particularly insightrul when forest monitoring has to be planned; it suggests that sampling the species composition of a given taxon in scattered plots across different sites might represent a more effective strategy in summarizing the whole community composition than sampling several plots at each site.

\section{I CONCLUSIONS}

Our results support the idea that cross-taxon congruence is highly dependent on spatial scale. We found the spatial extent to exert a greater influence on congruence between taxa than spatial grain, and species richness to be more sensitive to shifts in spatial scale than species composition. Plant species composition displayed the highest number of positive correlations with the composition of other taxonomic groups.

The sampling of multiple taxonomic groups is therefore necessary in forest biodiversity monitoring. However, based on our results, sampling plant species composition in individual plots scattered across different sites might represent a cost-effective strategy to summarize the information on the overall forest composition.

\section{ACKNOWLEDGMENTS}

This research was funded through different means. Data collected in central and southern Italy derive from the LIFE+ project FAGUS (11/NAT/IT/00135); those relative to Hungary from Hungarian Research Fund (OTKA K79158), Örség National Park Directorate; for the French Alps, funding came from IRSTEA and from the Con-seil Général de I'Isère and Bauges Natural Regional Park; data for the rest of France were collected with funding from the French Min-istry in charge of Ecology [Convention Cemagref-DEB (MEEDDAT), Action GNB and the programme 'Biodiversité, Gestion Forestière et Politiques Publiques' (BGF), convention GNB 10-MBGD-BGF-1-CVS-092, no CHORUS 2100 214 651] and the Office National des Forêts (Convention ONF-Cemagref, Action 5, 2008); data for north-ern Italy were collected with funding provided by the Italian Ministry of Agricultural, Food and Forestry Policies, State Forestry Corps (Project Managers: A. Andrighetti and D. Campedel), research agree-ment No. 767/2008 (T.S., Principal Investigator). Sapienza University of Rome provided the funding for the networking activities that allowed this joint research (Ricerche Universitarie 2015 - prot. C26A15KE2T). Above all, we wish to thank all the people who colla-borated in the fieldwork and in the species identification, without whom this work could not have been possible: Mattia M. Azzella, Hervé Brustel, Michele Cassol, Olivier Courtin, Marialuisa Dal Cortivo, Julien Delnatte, Laura Facioni, Gilles Favier, Enzo Gatti, Gino Gobbo, Julien Haran, Ildikó Király, Gergely Kutszegi, Sophie Labonne, Ferenc Lakatos, Edda Lattanzi, Fanny Lebagousse, Dario Lunghini, Zsuzsa Mag, Oriana Maggi, Sára Márialigeti, Carl Moliard, Balázs Németh, Thiemy Noblecourt, Benoit Nusillard, Fabio Padovan, Francesco Parisi, Sonia Ravera, Olivier Rose, Irén Siller, Monica Sommacal, Pascal Tardif, Agnese Tilia, Flóra Tinya and Mauro Varaschin.

\section{AUTHOR CONTRIBUTIONS}

S.B. developed the idea for this research. C.BI., C.Bo., S.B., T.C., F.G., P.J., J.N., Y.P., P.O. and T.S. contributed to the data. S.B., R.B.A., Y. P., P.O. and F.M.S. gathered and processed the data. A.M.P., G.A, J.N., S.B., Y.P. and P.O. checked the taxonomic nomenclature. R.BA. and Y.P. conducted the analyses. All the co-authors contributed to the writing of the manuscript.

\section{ORCID}

S.Burrascano http://orcid.org/0000-0002-6537-3313

R.deAndrade http://orcid.org/0000-0002-7976-7647

Y. Paillet http://orcid.org/0000-0001-7232-7844

P. Ódor https://orcid.org/0000-0003-1729-8897

G. Antonini https://orcid.org/0000-0002-7050-3696

T. Campagnaro https://orcid.org/0000-0002-6307-6892

J. Nascimbene https://orcid.org/0000-0002-9174-654X

F. M. Sabatini https://orcid.org/0000-0002-7202-7697

T. Sitzia https://orcid.org/0000-0001-6221-4256

REFERENCES

Barbier, S., Chevalier, R., Loussot, P., Bergès, L., \& Gosselin, F. (2009).

Improving biodiversity indicators of sustainable forest management: Tree genus abundance rather than tree genus richness and dominance for understory vegetation in French lowland oak hornbeam forests. Forest Ecology and Management, 258, S176 S186.

Barbier, S., Gosselin, F., \& Balandier, P. (2008). Influence of tree species on understory vegetation diversity and mechanisms involved $A$ 
critical review for temperate and boreal forests. Forest Ecology and Management, 254, 115.

Blasi, C., Marchetti, M., Chiavetta, U., Aleffi, M., Audisio, P., Azzella, M. M., ... Burrascano, S. (2010). Multi-taxon and forest structure sampling for identification of indicators and monitoring of old-growth forest. Plant Biosystems, 144, 160170.

Bouget, C., Larrieu, L., Nusillard, B., \& Parmain, G. (2013). In search of the best local habitat drivers for saproxylic beetle diversity in temperate deciduous forests. Biodiversity and Conservation, 22, 21112130.

Bouvet, A., Paillet, Y., Archaux, F., Tillon, L., Denis, P., Gilg, O., \& Gosselin, F. (2016). Effects of forest structure, management and landscape on bird and bat communities. Environmental Conservation, 43, 148 160.

Burrascano, S., Ripullone, F., Bernardo, L., Borghetti, M., Carli, E., Colangelo, M., ... Blasi, C. (2018). It's a long way to the top: Plant species diversity in the transition from managed to old-growth forests. Journal of Vegetation Science, 29, 98109.

Burrascano, S., Sabatini, F. M., \& Blasi, C. (2011). Testing indicators of sustainable forest management on understorey composition and diversity in southern Italy through variation partitioning. Plant Ecology, 212, 829841.

Campagnaro, T., Frate, L., Carranza, M. L., \& Sitzia, T. (2017). Multi-scale analysis of alpine landscapes with different intensities of abandonment reveals similar spatial pattern changes: Implications for habitat conservation. Ecological Indicators, 74, 147159.

Cornell, H. V., \& Harrison, S. P. (2014). What are species pools and when are they important? Annual Review of Ecology Evolution and Systematics, 45, 4567.

de Andrade, R. B., Barlow, J., Louzada, J., Mestre, L., Silveira, J., Vaz-deMello, F. Z., ... Cochrane, M. A. (2014). Biotic congruence in humid tropical forests: A multi-taxa examination of spatial distribution and responses to forest disturbance. Ecological Indicators, 36, 572581.

Gao, T., Nielsen, A. B., \& Hedblom, M. (2015). Reviewing the strength of evidence of biodiversity indicators for forest ecosystems in Europe. Ecological Indicators, 57, 420434.

Heilmann-Clausen, J., Aude, E., \& Christensen, M. (2005). Cryptogam communities on decaying deciduous wood Does tree species diversity matter? Biodiversity and Conservation, 14, 20612078.

Hess, G. R., Bartel, R. A., Leidner, A. K., Rosenfeld, K. M., Rubino, M. J., Snider, S. B., \& Ricketts, T. H. (2006). Effectiveness of biodiversity indicators varies with extent, grain, and region. Biological Conservation, 132, 448457.

Hodgetts, N. G. (2015). Checklist and country status of European bryophytes: Towards a new red list for Europe. Dublin, Ireland: National Parks and Wildlife Service.

Hsieh, T. C., Ma, K. H., \& Chao, A. (2016). iNEXT: An R package for rarefaction and extrapolation of species diversity (Hill numbers). Methods in Ecology and Evolution, 7, 14511456.

James, F. C., \& Wamer, N. O. (1982). Relationships between temperate forest bird communities and vegetation. Ecology, 63, 159171.

Janssen, P., Cateau, E., Fuhr, M., Nusillard, B., Brustel, H., \& Bouget, C. (2016). Are biodiversity patterns of saproxylic beetles shaped by habitat limitation or dispersal limitation? A case study in unfragmented montane forests. Biodiversity and Conservation, 25, 11671185.

Janssen, P., Fortin, D., \& Hébert, C. (2009). Beetle diversity in a matrix of old-growth boreal forest: Influence of habitat heterogeneity at multiple scales. Ecography, 32, 423432.

Juffe-Bignoli, D., Brooks, T. M., Butchart, S. H. M., Jenkins, R. B., Boe, K., Hoffmann, M., ... Kingston, N. (2016). Assessing the cost of global biodiversity and conservation knowledge. PLoS One, 11, e0160640.
Kempeneers, P., Sedano, F., Seebach, L., Strobl, P., \& San-Miguel-Ayanz, J. (2011). Data fusion of different spatial resolution remote sensing images applied to forest-type mapping. IEEE Transactions on Geoscience and Remote Sensing, 49, 49774986.

Kiraly, I., Nascimbene, J., Tinya, F., \& Odor, P. (2013). Factors influencing epiphytic bryophyte and lichen species richness at different spatial scales in managed temperate forests. Biodiversity and Conservation, 22, 209223.

Lewandowski, A. S., Noss, R. F., \& Parsons, D. R. (2010). The effectiveness of surrogate taxa for the representation of biodiversity. Conservation Biology, 24, 13671377.

Lindenmayer, D. B., Barton, P. S., Lane, P. W., Westgate, M. J., McBurney, L., Blair, D., ... Likens, G. E. (2014). An empirical assessment and comparison of species-based and habitat-based surrogates: A case study of forest vertebrates and large old trees. PLoS One, 9, e89807.

Márialigeti, S., Németh, B., Tinya, F., \& Ódor, P. (2009). The effects of stand structure on ground-floor bryophyte assemblages in temperate mixed forests. Biodiversity and Conservation, 18, 2223.

McCarthy, D. P., Donald, P. F., Scharlemann, J. P. W., Buchanan, G. M., Balmford, A., Green, J. M. H., ... Butchart, S. H. M. (2012). Financial costs of meeting global biodiversity conservation targets: Current spending and unmet needs. Science, 338, 946949.

Meier, E. S., Edwards, T. C. Jr., Kienast, F., Dobbertin, M., \& Zimmermann, N. E. (2011). Co-occurrence patterns of trees along macroclimatic gradients and their potential influence on the present and future distribution of Fagus sylvatica L. Journal of Biogeography, 38, 371382.

Miller, T. F., Mladenoff, D. J., \& Clayton, M. K. (2002). Old-growth northern hardwood forests: Spatial autocorrelation and patterns of understory vegetation. Ecological Monographs, 72, 487503.

Nakagawa, S., \& Cuthill, I. C. (2007). Effect size, confidence interval and statistical significance: A practical guide for biologists. Biological Reviews, 82, 591605.

Nimis, P. L., \& Martellos, S. (2008). ITALIC The information system on Italian lichens (version 4.0). Department of Biology, University of Trieste, IN4.0/1. Retrieved from http://dbiodbs.univ.trieste.it/http:// dbiodbs.univ.trieste.it/

Oksanen, J., Blanchet, F. G., Kindt, R., Legendre, P., Minchin, P. R., O'Hara, R. B., ... Wagner, H. (2016). vegan: Community ecology package. Retrieved from https://cran.r-project.org/web/packages/vegan/ index.html

Pearson, D. L. (1994). Selecting indicator taxa for the quantitative assessment of biodiversity. Philosophical Transactions of the Royal Society B: Biological Sciences, 345, 7579.

Pearson, D. L., \& Carroll, S. S. (1999). The influence of spatial scale on cross-taxon congruence patterns and prediction accuracy of species richness. Journal of Biogeography, 26, 10791090.

Peres-Neto, P. R., \& Jackson, D. A. (2001). How well do multivariate data sets match? The advantages of a Procrustean superimposition approach over the Mantel test. Oecologia, 129, 169178.

Pimm, S. L., Jenkins, C. N., Abell, R., Brooks, T. M., Gittleman, J. L., Joppa, L. N., ... Sexton, J. O. (2014). The biodiversity of species and their rates of extinction, distribution, and protection. Science, 344, 1246752.

Rivas-Martinez, S., \& Rivas-Saenz, S. (2009). Worldwide bioclimatic classification system, 1996 2009. Madrid, Spain: Phytosociological Research Center.

Sabatini, F. M., Burrascano, S., Tuomisto, H., \& Blasi, C. (2014). Ground layer plant species turnover and beta diversity in southern-European old-growth forests. PLoS One, 9, e95244.

Sætersdal, M., Gjerde, I., Blom, H. H., Ihlen, P. G., Myrseth, E. W., Pommeresche, R., ... Aas, O. (2004). Vascular plants as a surrogate species 
group in complementary site selection for bryophytes, macrolichens, spiders, carabids, staphylinids, snails, and wood living polypore fungi in a northern forest. Biological Conservation, 115, 2131.

Santi, E., Maccherini, S., Rocchini, D., Bonini, I., Brunialti, G., Favilli, L., ... Rota, E. (2010). Simple to sample: Vascular plants as surrogate group in a nature reserve. Journal for Nature Conservation, 18, 211.

Scheffers, B. R., Joppa, L N., Pimm, S. L., \& Laurance, W. F. (2012). What we know and don't know about Earth's missing biodiversity. Trends in Ecology and Evolution, 27, 501510.

Soininen, J., McDonald, R., \& Hillebrand, H. (2007). The distance decay of similarity in ecological communities. Ecography, 30, 312.

Supp, S. R., \& Ernest, S. K. M. (2014). Species-level and community-level responses to disturbance: A cross-community analysis. Ecology, 95, 17171723.

Svenning, J. C., \& Skov, F. (2002). Mesoscale distribution of understorey plants in temperate forest (Kalo, Denmark): The importance of environment and dispersal. Plant Ecology, 160, 169185.

Tews, J., Brose, U., Grimm, V., Tielborger, K., Wichmann, M. C., Schwager, M., \& Jeltsch, F. (2004). Animal species diversity driven by habitat heterogeneity/diversity: The importance of keystone structures. Journal of Biogeography, 31, 7992.

Tittensor, D. P., Walpole, M., Hill, S. L L, Boyce, D. G., Britten, G. L, Burgess, N. D., ... Alkemade, R. (2014). A mid-term analysis of progress toward international biodiversity targets. Science, 346, 241244.

Viechtbauer, W. (2010). Conducting meta-analyses in R with the metafor package. Journal of Statistical Software, 36, 148.

Westgate, M. J., Barton, P. S., Lane, P. W., \& Lindenmayer, D. B. (2014). Global meta-analysis reveals low consistency of biodiversity congruence relationships. Nature Communications, 5, 3899.

Westgate, M. J., Tulloch, A. I. T., Barton, P. S., Pierson, J. C., \& Lindenmayer, D. B. (2017). Optimal taxonomic groups for biodiversity assessment: A meta-analytic approach. Ecography, 40, 539548.
Willis, K. J., \& Whittaker, R. J. (2002). Species diversity Scale matters. Science, 295, 12451247.

Wolters, V., Bengtsson, J., \& Zaitsev, A. S. (2006). Relationship among the species richness of different taxa. Ecology, 87, 18861895.

Zobel, M., Szava-Kovats, R. C., \& Pärtel, M. (2011). Regional influences on local species composition. Encyclopedia of Life Sciences, 16.

\section{BIOSKETCH}

Our research team comprises a network of European scientists who shared structural and multi-taxonomic biodiversity data on temperate European forests to test the soundness and effectiveness of taxonand habitat-based indicators. Our ultimate goal is to inform conservation initiatives for forest biodiversity and sustainable management. We contribute to this goal through the integration of a wealth of skills and competencies that range from the in-depth knowledge of specific taxonomic groups to the general understanding of the pattems and processes that drive forest biodiversity.

\section{SUPPORTING INFORMATION}

Additional Supporting Information may be found online in the supporting information tab for this article.

How to cite this article: Burrascano S, de Andrade RB, Paillet $\mathrm{Y}$, et al. Congruence across taxa and spatial scales: Are we asking too much of species data? Global Ecol Biogeogr. 2018;27:980-990. https://doi.org/10.1111/geb.12766 